\title{
An Experimental Investigation of Leak Rate Performance of a Subscale Candidate Elastomer Docking Space Seal
}

Nicholas G. Garafolo and Christopher C. Daniels

The University of Akron, Akron, Ohio 


\section{NASA STI Program . . . in Profile}

Since its founding, NASA has been dedicated to the advancement of aeronautics and space science. The NASA Scientific and Technical Information (STI) program plays a key part in helping NASA maintain this important role.

The NASA STI Program operates under the auspices of the Agency Chief Information Officer. It collects, organizes, provides for archiving, and disseminates NASA's STI. The NASA STI program provides access to the NASA Aeronautics and Space Database and its public interface, the NASA Technical Reports Server, thus providing one of the largest collections of aeronautical and space science STI in the world. Results are published in both non-NASA channels and by NASA in the NASA STI Report Series, which includes the following report types:

- TECHNICAL PUBLICATION. Reports of completed research or a major significant phase of research that present the results of NASA programs and include extensive data or theoretical analysis. Includes compilations of significant scientific and technical data and information deemed to be of continuing reference value. NASA counterpart of peer-reviewed formal professional papers but has less stringent limitations on manuscript length and extent of graphic presentations.

- TECHNICAL MEMORANDUM. Scientific and technical findings that are preliminary or of specialized interest, e.g., quick release reports, working papers, and bibliographies that contain minimal annotation. Does not contain extensive analysis.

- CONTRACTOR REPORT. Scientific and technical findings by NASA-sponsored contractors and grantees.
- CONFERENCE PUBLICATION. Collected papers from scientific and technical conferences, symposia, seminars, or other meetings sponsored or cosponsored by NASA.

- SPECIAL PUBLICATION. Scientific, technical, or historical information from NASA programs, projects, and missions, often concerned with subjects having substantial public interest.

- TECHNICAL TRANSLATION. Englishlanguage translations of foreign scientific and technical material pertinent to NASA's mission.

Specialized services also include creating custom thesauri, building customized databases, organizing and publishing research results.

For more information about the NASA STI program, see the following:

- Access the NASA STI program home page at http://www.sti.nasa.gov

- E-mail your question via the Internet to help@ sti.nasa.gov

- Fax your question to the NASA STI Help Desk at $443-757-5803$

- Telephone the NASA STI Help Desk at 443-757-5802

- Write to: NASA Center for AeroSpace Information (CASI) 7115 Standard Drive Hanover, MD 21076-1320 


\section{An Experimental Investigation of Leak Rate Performance of a Subscale Candidate Elastomer Docking Space Seal}

Nicholas G. Garafolo and Christopher C. Daniels

The University of Akron, Akron, Ohio

Prepared for the

46th Joint Propulsion Conference and Exhibit

cosponsored by AIAA, ASME, SAE, and ASEE

Nashville, Tennessee, July 25-28, 2010

Prepared under Contract NNC08CA35C

National Aeronautics and

Space Administration

Glenn Research Center

Cleveland, Ohio 44135 


\section{Acknowledgments}

The authors greatly appreciate the contributions of Richard Tashjian. The material is based upon work supported by the National Aeronautics and Space Administration under Contract NNC08CA35C.

Trade names and trademarks are used in this report for identification only. Their usage does not constitute an official endorsement, either expressed or implied, by the National Aeronautics and Space Administration.

Level of Review: This material has been technically reviewed by NASA technical management.

Available from

NASA Center for Aerospace Information 7115 Standard Drive

Hanover, MD 21076-1320
National Technical Information Service 5301 Shawnee Road Alexandria, VA 22312

Available electronically at http://www.sti.nasa.gov 


\title{
An Experimental Investigation of Leak Rate Performance of a Subscale Candidate Elastomer Docking Space Seal
}

\author{
Nicholas G. Garafolo and Christopher C. Daniels \\ The University of Akron \\ Akron, Ohio 44325
}

\begin{abstract}
A novel docking seal was developed for the main interface seal of NASA's Low Impact Docking System (LIDS). This interface seal was designed to maintain acceptable leak rates while being exposed to the harsh environmental conditions of outer space. In this experimental evaluation, a candidate docking seal assembly called Engineering Development Unit (EDU58) was characterized and evaluated against the Constellation Project leak rate requirement. The EDU58 candidate seal assembly was manufactured from silicone elastomer S0383-70 vacuum molded in a metal retainer ring. Four seal designs were considered with unique characteristic heights. The leak rate performance was characterized through a mass point leak rate method by monitoring gas properties within an internal control volume. The leakage performance of the seals were described herein at representative docking temperatures of $-50,+23$, and $+50^{\circ} C$ for all four seal designs. Leak performance was also characterized at 100, 74, and $48 \%$ of full closure. For all conditions considered, the candidate seal assemblies met the Constellation Project leak rate requirement.
\end{abstract}

\section{Nomenclature}

$\begin{array}{llll}a & \text { Regression coefficient } & R T D & \text { Resistance temperature device } \\ A O & \text { Atomic oxygen } & t & \text { Time } \\ B & \text { Bias error } & T M L & \text { Total mass loss } \\ C B M & \text { Common Berthing Mechanism } & T & \text { Temperature } \\ C V C M & \text { Collected volatile condensable materials } & U & \text { Uncertainty } \\ E D U 58 & \text { Engineering Development Unit } & U V & \text { Ultraviolet } \\ h & \text { height } & V & \text { Volume } \\ L I D S & \text { Low Impact Docking System } & x & \text { bulb location } \\ N A S A & \text { National Aeronautics and Space Adminstration } & & \\ m & \text { Mass } & 0 & \\ p & \text { Pressure } & 1 & \text { zeroth order } \\ P & \text { Precision error } & b u l b & \text { bulb order } \\ R & \text { Specific gas constant } & \dot{m} & \text { Mass Leak Rate }\end{array}$

\section{Introduction}

$\mathrm{T}$ HE National Aeronautics and Space Adminstration (NASA) developed a new docking system for spacecraft. This system, called the Low Impact Docking System (LIDS), was expected to provide the interface between pressurized manned and autonomous vehicles. ${ }^{1}$ Novel elastomer seals were developed for the main interface seal of LIDS. The characterization of developmental seals was necessary to ensure the safety of both astronauts and spacecraft equipment. 
LIDS has three large seal interfaces: the bottom-tunnel seal, the mid-tunnel seal, and the main interface docking seal. Illustrations of the seal locations are shown in Figure 1. One seal was located the bottom of the docking system and provides the seal for joining the LIDS to the vehicle. The mid-tunnel seal was integral to the LIDS and joins two components of the LIDS. The seal at the top of the LIDS was the main interface seal and provides the interface for attaching one LIDS equipped vehicle to another LIDS equipped vehicle.

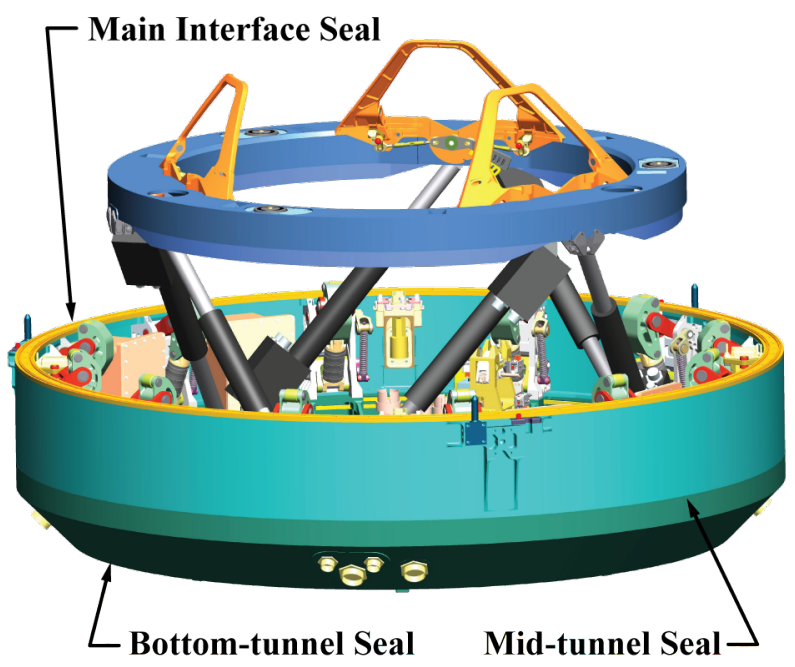

Figure 1. Illustration of the Low Impact Docking System

The main interface seal assembly, located at the top of the approximate $58 \mathrm{in}$. diameter docking system, was a quasi-static counter-face seal. This interface is designed to be joined and separated when the spacecraft docks and undocks during its mission. The seal must remain operational through repeated docking/undocking operations while also being capable of withstanding the operating load, pressure, and temperature environments.

Each of the three seals was a vacuum seal and must inhibit transport of atmospheric pressure air from within the spacecraft to its exterior (i.e., the seals must prevent the loss of air from the inside diameter of the seal while the exterior of the seal was exposed to the vacuum pressure of space). The maximum allowable leak rate of the LIDS main interface seal was $0.0025 l b_{m \text {,air }}$ per day. This volume of air $\left(0.0025 l b_{m, a i r}\right)$ was equivalent to approximately 80 in. ${ }^{3}$ at standard temperature and pressure. For a 58 in. diameter seal, the maximum allowable leak rate scales to $1.4 \mathrm{E}-5 \frac{l b_{m, a i r}}{d a y-i n}$. With the very low value of allowable leak rate, permeation of gas through the seal material was of concern and was minimized. As the LIDS and its main interface seal operate in a vacuum pressure environment, all materials must conform to NASA-STD-(I)$6016 .^{2}$ This standard mandates that outgas byproducts be limited to less than $1.0 \%$ total mass loss (TML) and less than $0.1 \%$ collected volatile condensable materials (CVCM) when exposed to heat and vacuum pressures, as tested following the ASTM E595-076. ${ }^{3}$

The amount of force required to fully compress the LIDS main interface seal must be less than $140 \mathrm{lbf}$ per linear inch of seal. This requirement was dictated by the latching capacity of the docking system. The mid-tunnel and bottom-tunnel seals are not held to these requirements. The LIDS main interface seal must be able to accommodated 80 docking and undocking cycles during its lifetime.

Elastomer seals provide a means to create a joint that has very low leak rates across the seal while maintaining the ability to be used repeatedly. Additionally, elastomer seals can be relatively low cost compared with other types of seals (e.g., metal seals). As the LIDS was developed to be used while in lowEarth orbit, during Trans Lunar travel, and while orbiting the Moon, the seal assemblies must be compatible with a wide range of environments. Atomic oxygen (AO) is highly reactive species and is present in low-Earth orbit. AO reacts with the surface of an elastomer seal and can embrittle the surface.

Ultraviolet (UV) radiation emitted directly from the Sun, combined with the albedo from the surface of the Earth and Moon, penetrates the bulk solid of an elastomer seal and breaks the long flexible molecular chains. The resultant short inflexible molecules tend to be brittle and can lead to cracking. The vacuum pressure can evolve the elastomer compound and continually change its properties with exposure. The 
environmental temperature of the LIDS was expected to be -100 to $+125^{\circ} \mathrm{C}$. The seal would not be required to seal across the entire exposure temperature, but it would be expected to operate across a -50 to $+50^{\circ} \mathrm{C}$ temperature range. These requirements and exposure environments severely limit the choices of compounds suitable for docking seal applications. Therefore, the decision was made to pursue the development of silicone elastomer compound seals. These types of seals are capable of achieving very low leak rates when used as counter-face seal. They are compatible with the space environment for their expected lifetime. Select compounds are able to meet the low outgassing specifications, while most silicones can withstand the thermal environment.

The choice to use silicone, however, has the negative aspect of increased permeation through the material. Silicone is known to have a high permeation rate with respect to other typical seal material compounds. This increase in the permeation is mitigated through design.

One candidate seal is the Gask-O-Seal ${ }^{\circledR}$, manufactured by Parker Hannifin Corporation. Gask-O-Seals ${ }^{\circledR}$ are a composite design; the elastomer compound was vacuum molded into an aluminum retainer. The seal was held into position using fasteners mounted through the metal member of the composite seal, see Figure 2 .

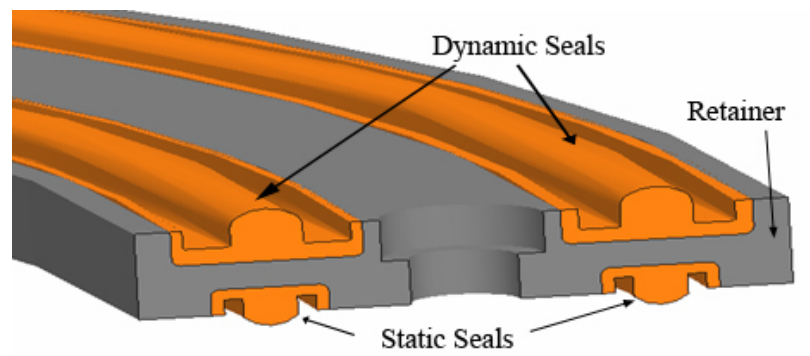

Figure 2. Illustration of EDU58 series cross section.

Experimental studies have been conducted on Gask-o-Seals ${ }^{\circledR}$ with several differing geometries and elastomer compounds, aimed at understanding the behavior of the elastomer and the leak rates corresponding to the different operating conditions that may occur during the seals lifetime. Subscale versions of the Common Berthing Mechanism (CBM) and initial Engineering Development Unit (EDU54) have been experimentally evaluated by Smith. ${ }^{4}$ It has been shown that the leak rate of elastomer seals depends greatly on temperature. An increase increase in temperature results in an increase in leak rate. Previous docking seals, such as those used on the CBM, have met the maximum leak rate requirement. Examinations have also been conducted to characterize the leak rate and adhesion of elastomer after exposure to $\mathrm{AO}$ and UV radiation. ${ }^{5}$ Leak rate dependencies on closure level have also been studied by Smith. ${ }^{4}$ An increase in the level of closure (i.e., incomplete compression) increases the sealing performance of the candidate seal. In addition to the subscale studies noted above, near full-scale seals have been characterized and behaved similarly. ${ }^{6-8}$

The primary mechanism of air leakage from the main interface docking seal was permeation, where the largest contributing leakage was found through the seal rather than flow through the seal/counter-face mating interface. ${ }^{4}$ Permeability is the measure of momentum transport in porous media. ${ }^{9}$ Here, air travels through elastomer bulb. Permeation consists of two components, diffusion and advection. Diffusive permeation is transport driven by concentration gradients, whereas advective permeation is driven by pressure gradients. A compressible permeation approach to space seal research that encompassed both diffusion and advection was recently developed. ${ }^{10-12}$

The objective of the research presented herein was to characterize the sealing performance of the Engineering Development Unit (EDU58) series of docking seals under simulated operating conditions in temperature and level of closure.

\section{Experimental Setup}

A series of experiments were conducted to characterize the leak rates of subscale candidate docking seals at specific temperatures and differing levels of compression in an elastomer on metal plate configuration. The experimental setup and procedure are detailed herein. 


\section{A. Test Specimens}

The subscale candidate docking seals were Gask-O-Seals ${ }^{\circledR}$ manufactured by the Composite Sealing Systems Division of the Parker Hannifin Corporation. The seals were composite seals comprised of four elastomer bulbs vacuum molded into a metal retainer ring. An illustration of the seal showing a cross section of the molded elastomer and retainer ring is shown in Figure 2. The elastomer compound was S0383-70, manufactured by the Parker Hannifin Corporation. The metal retainer ring was manufactured from aluminium 6061-T651, which was anodized for improved corrosion resistance. The subscale test specimens were approximately $12 \mathrm{in.}$ on the outside diameter. Photographs of the front side and back side of a sample test specimen are shown in Figure 3(a) and 3(b), respectively.

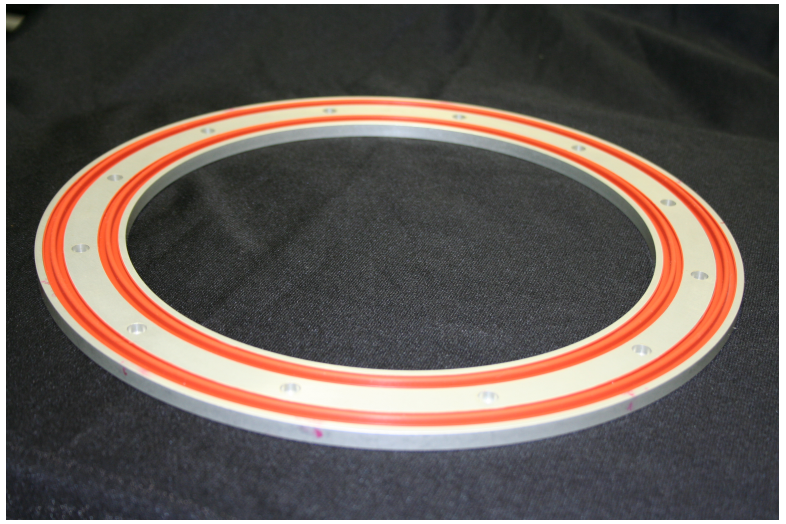

(a) Front side, dynamic seal

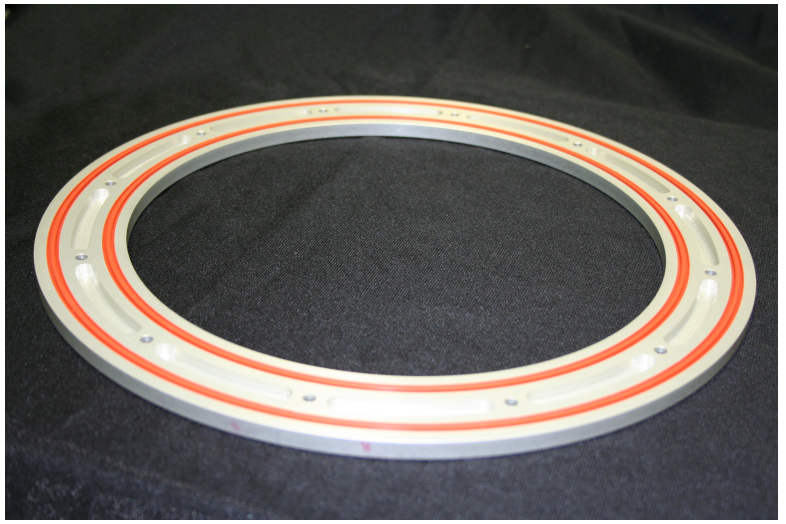

(b) Back side, static seal

Figure 3. Photograph of a subscale EDU58 test specimen.

Four bulb designs were tested. Each design had a unique and proprietary bulb height. Furthermore, the seal designs have increasing bulb heights and are noted as EDU58-1, EDU58-2, EDU58-3, and EDU58-4, respectively. The elastomer compound used for the seal bulb was verified to meet the low outgas requirements with total mass loss (TML) and collected volatile condensable materials (CVCM) values below the limits of $1.0 \%$ and $0.1 \%$., respectively, ${ }^{13}$ as dictated by NASA-STD-I- $6016^{2}$ and tested per ASTM E595. ${ }^{3}$

\section{B. Test Apparatus}

The test apparatus consisted of two plates, hermetic plumbing, and the required sensors. The test specimen was clamped between two stainless steel plates with a surface finish of $16 \mu \mathrm{in}$. or better, creating an internal control volume. The seal was attached to the bottom plate with twelve 8-32 screws, compressing the back side, static seals to full closure. An illustration of the two plates clamped onto the seal is shown in Figure 4. The top plate had a vent port located between the inner and outer bulbs. This allowed for isolation and characterization of the inner seal. Dry air was supplied to the inner control volume. The pressure of this control volume was monitored by two pressure transducers with a full scale accuracy of $0.75 \%$ at a range of $0-35$ psia. Temperature was monitored with an resistance temperature device (RTD) with an accuracy of $\pm 0.2^{\circ} \mathrm{C}$. The RTD was inserted into a small aluminum block, mounted to the stainless steel plate, and insulated from the environment in a foam block. The apparatus was enclosed in a Tenney BenchmasterBTRC environmental chamber. The environmental chamber had a temperature range of -73 to $+200^{\circ} \mathrm{C}$ with a control accuracy of $\pm 0.3^{\circ} \mathrm{C}$. The installation of the test specimen to the bottom plate of the test apparatus is shown in Figure 5.

In order to simulate different levels of closure of the front side, dynamic seal, shims of a known value were placed between the two fixture plates. The shims were located around the circumference of the fixture and equidistant from each other. The leak rates were characterized at 100, 74, and $48 \%$ closure, where closure is defined in Equation 1.

$$
\text { closure }=\frac{h_{\text {bulb }}-x}{h_{\text {bulb }}} \times 100 \%
$$




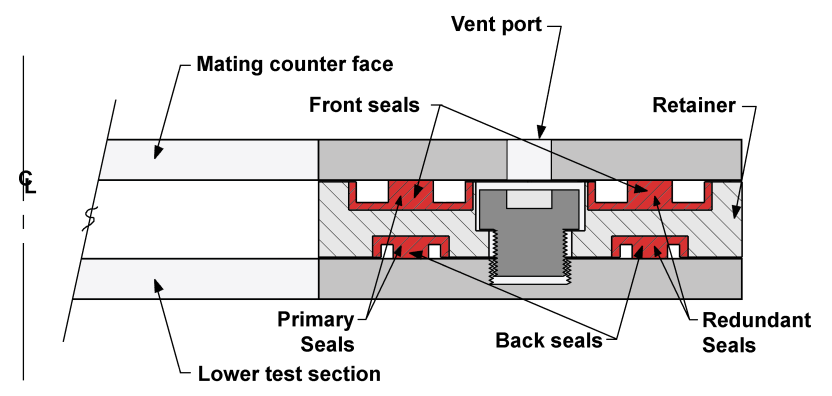

Figure 4. Illustration of two plates clamped onto a seal assembly.

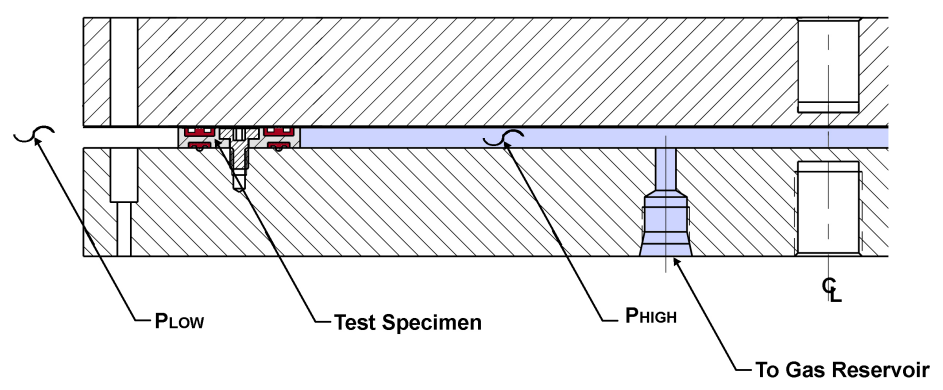

Figure 5. Illustration of test apparatus with creation of inner control volume.

where $x$ is the distance between the metal retainer and the mating counter-face at the desired closure level and $h_{\text {bulb }}$ is the uncompressed bulb height above the retainer. Note, full closure was metal to metal contact between the top plate and the metal retainer ring.

\section{Leak Rate Calculation}

The mass point leak rate method was implemented to quantify the leak rate of the subscale candidate space seals. Pressure and temperature measurements of known inner control volume of gas were monitored over time. Utilizing the ideal gas law and the definition of specific volume, the mass $(m)$ was calculated through measurements of pressure $(p)$, temperature $(T)$, volume $(V)$, compressibility factor $(Z)$, and the specific gas constant $(R)$.

$$
m=\frac{p_{\text {absolute } V}}{(Z R T)}
$$

The compressibility factor, $Z$, equal to unity was appropriate for this application, as the temperature was below $2 \times 10^{3} K^{14}$

Leak rate analyses require a population of mass sample points with corresponding time stamp. An appropriate regression analysis on the population directly yields the leak rate in units of mass over time (e.g., $\frac{l b_{m, a i r}}{\text { day }}$. As calculated in Equation 2, the mass at each time step was determined, $\left(t_{i}, m_{i}\right)$. A regression analysis of the mass-time population yielded the coefficients of the linear decay model: ${ }^{15}$

$$
m(t)=a_{1} t+a_{0}
$$

where $m$ was the mass of the control volume as a function of time $(t), a_{1}$ was the leak rate, and $a_{0}$ was the initial mass of the control volume and was of no consequence. The coefficient $a_{1}$ was determined through a least-squares regression shown in Equation $4 .{ }^{16}$

$$
a_{1}=\frac{n \sum_{i=1}^{n}\left(t_{i} m_{i}\right)-\sum_{i=1}^{n}\left(t_{i}\right) \sum_{i=1}^{n}\left(m_{i}\right)}{n \sum_{i=1}^{n}\left(t_{i}^{2}\right)-\left(\sum_{i=1}^{n}\left(t_{i}\right)\right)^{2}}
$$


The corresponding leak rate per linear inch of seal was determined by dividing the total leak rate by the mean circumference of the inner bulb. All leaks were attributed to permeation though the seal, rather than test apparatus leaks or flow across the seal interface. The complete methodology, including uncertainty analysis was detailed by Garafolo ${ }^{17}$ and Daniels. ${ }^{18}$

\section{Uncertainty Analysis}

An uncertainty analysis is imperative for a quantifiable level of confidence in the leak rate measurement. In addition to the value of the space seal leak rate, the system uncertainty (bias error), the random uncertainty (precision error), and the confidence level must be reported. ${ }^{15}$ Each measurement has it own bias and precision error. In this analysis, all bias and precision errors are assumed independent from each other. A comprehensive explanation of detailed uncertainty analysis can be found in Coleman ${ }^{15}$ and with direct application to leak rate measurements in Comprehensive Mass Point Leak Rate Technique. ${ }^{17,18}$

The uncertainty analysis of the leak rate calculation included the variability in the measurement devices on the least-squares regression ${ }^{15,19,20}$ and is shown in Equation 5. The uncertainties for each elemental measurement (i.e., pressure, temperature, time) were calculated from calibration records or manufacturer stated accuracies and propagated through to the calculation of mass, Equation 2. The comprehensive uncertainty analysis contained measures of covariance, $B_{m_{i} m_{k}}, B_{t_{i} t_{k}}$, and $B_{t_{i} m_{k}}$. In this study, the covariances were assumed neglectible, as each transducer was assumed completely independent of from another and that there was no covariance with the data acquisition's time control. Further discussions of these covariances are found in Coleman ${ }^{15}$ and Brown. ${ }^{21}$ This uncertainty, $U_{\dot{m}}$, is the uncertainty of the leak rate and is often given as a percentage, $u_{\dot{m}} \cdot{ }^{22}$

$$
\begin{aligned}
U_{\dot{m}}^{2}= & \sum_{i=1}^{n}\left(\frac{\partial a_{1}}{\partial m_{i}}\right)^{2} P_{m_{i}}^{2}+\sum_{i=1}^{n}\left(\frac{\partial a_{1}}{\partial t_{i}}\right)^{2} P_{t_{i}}^{2}+\sum_{i=1}^{n}\left(\frac{\partial a_{1}}{\partial m_{i}}\right)^{2} B_{m_{i}}^{2}+2 \sum_{i=1}^{n-1} \sum_{k=i+1}^{n}\left(\frac{\partial a_{1}}{\partial m_{i}}\right)\left(\frac{\partial a_{1}}{\partial m_{k}}\right) B_{m_{i} m_{k}} \\
+ & \sum_{i=1}^{n}\left(\frac{\partial a_{1}}{\partial t_{i}}\right)^{2} B_{t_{i}}^{2}+2 \sum_{i=1}^{n-1} \sum_{k=i+1}^{n}\left(\frac{\partial a_{1}}{\partial t_{i}}\right)\left(\frac{\partial a_{1}}{\partial t_{k}}\right) B_{t_{i} t_{k}}+2 \sum_{i=1}^{n-1} \sum_{k=i+1}^{n}\left(\frac{\partial a_{1}}{\partial t_{i}}\right)\left(\frac{\partial a_{1}}{\partial m_{k}}\right) B_{t_{i} m_{k}}
\end{aligned}
$$

\section{Experimental Results and Discussion}

The leak rate per linear inch of bulb length was determined for the 12 in. EDU58 -1,-2,-3, and -4 docking seal assemblies at select temperatures and closure levels representative of operating environment. For all conditions investigated, the leak rate performance for each seal assembly met all design requirements as outline above. The maximum observed leak rate of $2.30 \mathrm{E}-6 \frac{l b_{m, a i r}}{d a y-i n}$, found at $+50^{\circ} \mathrm{C}$ and $48 \%$ closure, was well below the requirement of $1.4 \mathrm{E}-5 \frac{l b_{m, a i r}}{d a y-i n}$. Results and discussion on the effects of temperature, design, closure, and seal design repeatability are detailed.

\section{A. Effects of temperature on leak rate}

Temperature had as significant effect on the leak rate performance of each seal; an increase in leak rate correlated to an increase in temperature. The average leak rate values per linear inch of bulb for candidate seal designs at three test temperatures are shown in Figure 6 . For a given design, the $95 \%$ confidence interval for a given design's leak rate did not overlap with the $95 \%$ confidence interval of the same design at a different temperature. This suggested that there was a statistical difference between the leak rate values at the select temperatures.

The increase in leak rate was attributed to the an increase in the permeability of the elastomer and was supported by permeation modeling of elastomeric space seals. ${ }^{11}$ The elastomer undergoes thermal expansion with an increase in test temperature, thus increasing the effective bulb width. However, the temperature effects on permeability overcome any sealing benefits in geometric changes due to thermal expansion.

\section{B. Effects of Design}

Experimental testing suggested a dependency of the leak rate on the characteristic bulb height between the EDU58 series seals. An increase in bulb height correlated with a decrease in the observe leak rate 


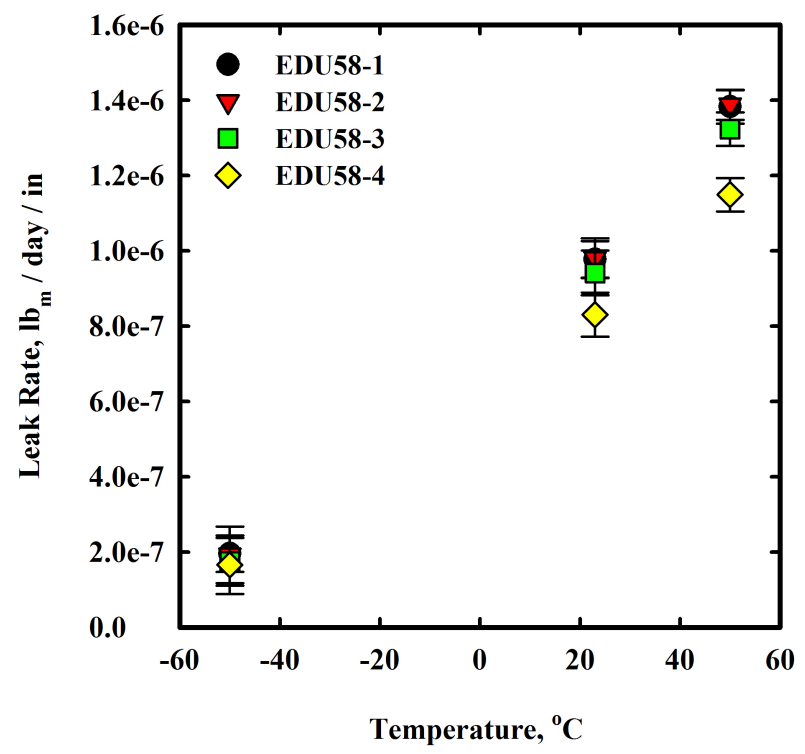

Figure 6. Comparison of average leak rates for four EDU58 seal designs at temperatures.

value, Figure 6. This was expected, as the effective seal width was wider for taller bulbs under the same displacement.

Save for the EDU58-4 seal at $+50^{\circ} \mathrm{C}$, there was no significant statistical difference at each temperature for the four seal assembly designs. Although it was possible to differentiate the observed leak rate values between each design, there was commonality in $95 \%$ confidence interval. It is suggested that if the fidelity of the test apparatus and data acquisition system were increased, the differences in leak rate values of the three designs would be statically significant.

It is important to note, however, that the leak rate performance is not the only metric used in the the selection of a main interface seal. The force required for full closure also needs consideration. ${ }^{23}$

\section{Effects of closure levels on leak rate}

The effects of closure level on the leak rate were determined at 100, 74 , and $48 \%$ of full compression, as defined in Equation 1, for an EDU58-3 seal assembly design at each temperature. Result showed a strong dependency of compression level on leak rate, Figure 7. A decrease in closure increased the leak rate; the decrease in percent closure shortens the permeation pathway for the gas to travel and increases with wetted area available. A strong correlation between leak rate and temperature, regardless of compression level, was developed. The difference in the leak rate performance between the selected closure levels were statistically significant for $+23^{\circ} \mathrm{C}$ and $+50^{\circ} \mathrm{C}$ operating temperatures; the confidence intervals did not overlap. For the $-50^{\circ} \mathrm{C}$, differences in the leak rate were observed, however, they were not statistically significant.

\section{Design Repeatability}

Design manufacturing repeatability was investigated using three different seal assemblies of the same design, namely EDU58-3. The leak rates were characterized at three test temperatures $\left(-50,+23\right.$, and $\left.+50^{\circ} \mathrm{C}\right)$ and in duplicate, for a total of six test points per temperature. Results are shown graphically in Figure 8. Given the $95 \%$ confidence interval, there was commonality in each observed leak rate of the three different EDU58-3 seals for a given temperature. This measure suggests that leak rate values of multiple seals within a specific design were not statistically different. 


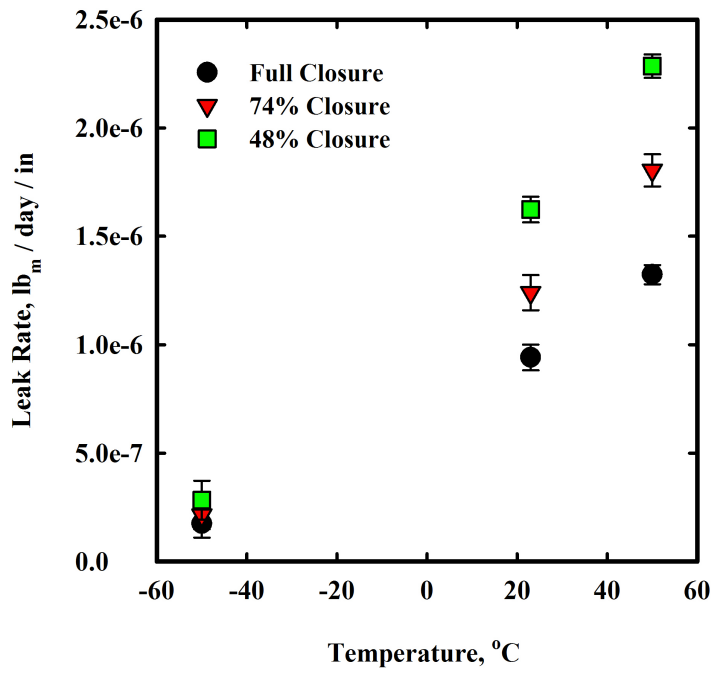

Figure 7. Average leak rates for EDU58-3 seal assembly at temperatures and various compression levels.

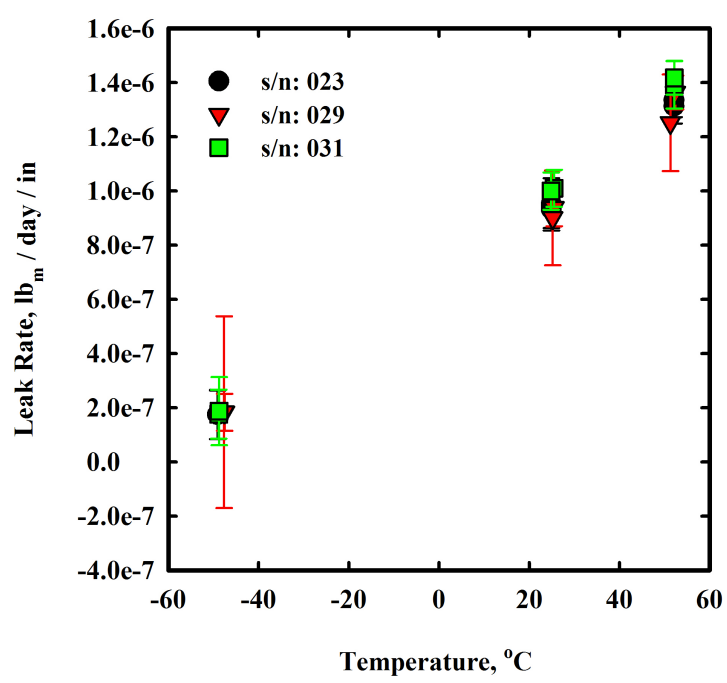

Figure 8. Leak rates of three EDU58-3 seal assemblies at temperatures.

\section{Conclusion}

The performance characterization of pressure seals in spacecraft is imperative for manned spaceflight. Seals must meet or exceed acceptable air losses in a harsh vacuum environment over extreme operating conditions. A performance characterization of a candidate seal assembly for the main interface seal of the Low Impact Docking System was performed with four seals of the EDU58 design series in various compression and temperature conditions.

The following conclusions were supported with this experimental investigation:

- There exists a dependence of leak rate on temperature. An increase in test temperature was shown to increase the leak rate. The temperature effects on permeability overcome any sealing benefits in geometric changes due to thermal expansion.

- There exists a dependance of leak rate on compression. Results showed that a decrease in the level of compression increases the leak rate.

- A dependency of the leak rate on seal design was suggested. However, the leak rates of the designs were not statically different at a given temperature. It was suggested that an increase in the fidelity of the test apparatus and data acquisition system may differentiate the seal designs.

- The EDU58 series seal design met program performance requirements for all seal designs and temperatures investigated.

\section{References}

${ }^{1}$ Lewis, J. L., Carroll, M. B., Morales, R. H., Thang, D. L., and National Aeronautics and Space Administration, Washington, D. C., "Androgynous, Reconfigurable Closed Loop Feedback Controlled Low Impact Docking System with Load Sensing Electromagnetic Capture Ring," United States of America Patent No. 6,354,540, 12 March 2002.

${ }^{2}$ National Aeronautics and Space Administration, "NASA-STD-(I)-6016 :Standard Materials and Processes Requirements for Spacecraft, Expires September 2007," 2007.

${ }^{3}$ ASTM International, "ASTM E595-07 (Reapproved 2003): Standard test method for total mass loss and collected volatile condensable materials from outgassing in a vacuum environment," 2003.

${ }^{4}$ Smith, I. M., Daniels, C. C., Dunlap, P. H., and Steinetz, B. M., "Performance of Sub-scale Docking Seals under Simulated Temperature Conditions," Proceedings of the 44rd AIAA / ASME / SAE / ASEE Joint Propulsion Conference E Exhibit, No. AIAA 2008-4713, 2008 
${ }^{5}$ Daniels, C. C., de Groh III, H., Dunlap, P. H., Finkbeiner, J. R., Steinetz, B. M., Bastrzyk, M. B., Oswald, J. J., Banks, B. A., Dever, J. A., Miller, S. K., and Waters, D. L., "Characteristics of Elastomer Seals Exposed to Space Environments," Proceedings of the 43rd AIAA / ASME / SAE / ASEE Joint Propulsion Conference \& Exhibit, No. AIAA 2007-5741, 2007.

${ }^{6}$ Dunlap, Jr., P. H., Daniels, C. C., Steinetz, B. M., Erker, A. H., Robbie, M. G., Wasowski, J. L., Drlik, G. J., Tong, M. T., and Penney, N., "Full-Scale System for Quantifying Leakage of Docking System Seals for Space Applications," Proceedings of the 43rd AIAA / ASME / SAE / ASEE Joint Propulsion Conference ES Exhibit, No. AIAA 2007-5742, 2007.

${ }^{7}$ Dunlap, Jr., P. H., Daniels, C. C., Wasowski, J. L., , Garafolo, N. G., Penney, N., and Steinetz, B. M., "Full-Scale System and Testing Methodology for Quantifying Leak Rates of Docking System Seals for Space Applications," Proceedings of the 45th AIAA / ASME / SAE / ASEE Joint Propulsion Conference E Exhibit, No. AIAA 2009-5319, 2009.

${ }^{8}$ Wasowski, J. L., Penney, N., Garafolo, N. G., and Daniels, C. C., "Leak Rates of a Candidate Main Interface Seal at Selected Temperatures," Proceedings of the 45th AIAA / ASME / SAE / ASEE Joint Propulsion Conference ES Exhibit, No. AIAA 2009-5320, 2009.

${ }^{9}$ Ho, C. K. and Webb, S. W., editors, Gas Transport in Porous Media, Springer, 2006.

${ }^{10}$ Garafolo, N. G. and Daniels, C. C., "Compressible advection through an elastomer seal: a porous media approach to seals for space applications," Proceedings of the ASME 2009 Fluids Engineering Division Summer Meeting, No. FEDSM2009-78067, ASME, Vail, CO, 2-5 August 2009.

${ }^{11}$ Garafolo, N. G., A Compressible Advection Approach in Permeation of Elastomer Space Seals, Ph.D. Dissertation, The University of Akron, May 2010.

${ }^{12}$ Garafolo, N. G. and Daniels, C. C., "A Complete Permeation Approach to Elastomer Face Seal Characterization," ASME Journal of Fluids Engineering, Vol. under preparation, 2010.

${ }^{13}$ Daniels, C. C., Oswald, J. J., Bastrzyk, M. B., Smith, I. M., Patrick H. Dunlap, J., and Steinetz, B. M., "Experimental Investigation of Elastomer Docking Seal Compression Set, Adhesion, and Leakage," Proceedings of the AIAA Space 2007 Conference and Exposition, No. AIAA-2007-6197, 2007.

${ }^{14}$ Hansen, F., "Approximations for the Thermodynamic and Transport Properties of High-Temperature Air," National Advisory Committee for Aeronatautics, , No. Technical Note 4150, March 1958.

${ }^{15}$ Coleman, H. W. and Steele, Jr., W. G., Experimentation and Uncertainity Analysis for Engineers, John Wiley \& Sons, Inc., 2nd ed., 1999.

${ }^{16}$ Chapra, S. C. and Canale, R. P., Numerical Methods for Engineers, The McGraw-Hill Companies, Inc., 4th ed., 2002.

${ }^{17}$ Garafolo, N. G. and Daniels, C. C., "Comprehensive Mass Point Leak Rate Technique. Part I: Methodology with Uncertainty and Experimental Error Analysis," JSNDI/ASNT Fourth Japan - US Symposium on Emerging NDE Capabilites for a Safer World, 2010.

${ }^{18}$ Daniels, C. C. and Garafolo, N. G., "Comprehensive Mass Point Leak Rate Technique. Part II: Application of Methodology and Variable Influences," JSNDI/ASNT Fourth Japan - US Symposium on Emerging NDE Capabilites for a Safer World, 2010.

${ }^{19}$ Brown, K. K., Assessment of the Experimental Uncertainty Associated with Regression, Ph.D. thesis, The University of Alabama in Huntsville, Huntsville, Alabama, 1996.

${ }^{20}$ Brown, K. K., Coleman, H. W., and Steele, Jr., W. G., "A Methodology for Determining Experimental Uncertainties in Regressions," Journal of Fluids Engineering, Vol. 120, September 1998, pp. 445-456.

${ }^{21}$ Brown, K. K., Coleman, H. W., Steele, W. G., and Taylor, R. P., "Evaluation of Correlated Bias Approximations in Experimental Uncertainty Analysis," AIAA Journal, Vol. 34, No. 5, May 1996, pp. 1013-1018.

${ }^{22}$ Figliola, R. S. and Beasley, D. E., Theory and Design for Mechanical Measurments, John Wiley \& Sons, Inc., 3rd ed., 2000.

${ }^{23}$ Bastrzyk, M. B. and Daniels, C. C., "The Mechanical Performance of Subscale Candidate Elastomer Docking Seal," Proceedings of the 51st AIAA Materials Conference, No. AIAA 2010-3129, AIAA, Orlando, FL, 12-15 April 2010. 


\begin{tabular}{|c|c|c|}
\hline \multicolumn{2}{|c|}{ REPORT DOCUMENTATION PAGE } & $\begin{array}{l}\text { Form Approved } \\
\text { OMB No. 0704-0188 }\end{array}$ \\
\hline \multicolumn{3}{|c|}{ 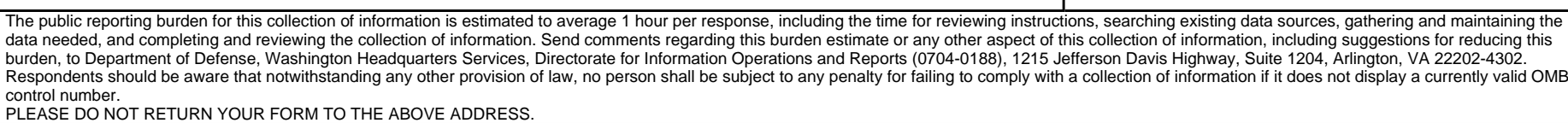 } \\
\hline $\begin{array}{l}\text { 1. REPORT DATE (DD-MM-YYYY) } \\
01-11-2011\end{array}$ & $\begin{array}{l}\text { 2. REPORT TYPE } \\
\text { Final Contractor Report }\end{array}$ & 3. DATES COVERED (From - To) \\
\hline \multirow{3}{*}{\multicolumn{2}{|c|}{$\begin{array}{l}\text { 4. TITLE AND SUBTITLE } \\
\text { An Experimental Investigation of Leak Rate Performance of a Subscale Candidate Elastomer } \\
\text { Docking Space Seal }\end{array}$}} & $\begin{array}{l}\text { 5a. CONTRACT NUMBER } \\
\text { NNC08CA35C }\end{array}$ \\
\hline & & 5b. GRANT NUMBER \\
\hline & & 5c. PROGRAM ELEMENT NUMBER \\
\hline \multirow{3}{*}{\multicolumn{2}{|c|}{$\begin{array}{l}\text { 6. AUTHOR(S) } \\
\text { Garafolo, Nicholas, G.; Daniels, Christopher, C. }\end{array}$}} & 5d. PROJECT NUMBER \\
\hline & & 5e. TASK NUMBER \\
\hline & & $\begin{array}{l}\text { 5f. WORK UNIT NUMBER } \\
\text { WBS 644423.06.31.04.01.03.22 }\end{array}$ \\
\hline \multicolumn{2}{|c|}{$\begin{array}{l}\text { 7. PERFORMING ORGANIZATION NAME(S) AND ADDRESS(ES) } \\
\text { The University of Akron } \\
302 \text { Buchtel Mall } \\
\text { Akron, Ohio } 44325\end{array}$} & $\begin{array}{l}\text { 8. PERFORMING ORGANIZATION } \\
\text { REPORT NUMBER } \\
\text { E-17457 }\end{array}$ \\
\hline \multirow{2}{*}{\multicolumn{2}{|c|}{$\begin{array}{l}\text { 9. SPONSORING/MONITORING AGENCY NAME(S) AND ADDRESS(ES) } \\
\text { National Aeronautics and Space Administration } \\
\text { Washington, DC 20546-0001 }\end{array}$}} & $\begin{array}{l}\text { 10. SPONSORING/MONITOR'S } \\
\text { ACRONYM(S) } \\
\text { NASA }\end{array}$ \\
\hline & & $\begin{array}{l}\text { 11. SPONSORING/MONITORING } \\
\text { REPORT NUMBER } \\
\text { NASA/CR-2011-216829 }\end{array}$ \\
\hline \multicolumn{3}{|c|}{$\begin{array}{l}\text { 12. DISTRIBUTIONIAVAILABILITY STATEMENT } \\
\text { Unclassified-Unlimited } \\
\text { Subject Categories: } 18 \text { and } 37 \\
\text { Available electronically at http://wWw.sti.nasa.gov } \\
\text { This publication is available from the NASA Center for AeroSpace Information, 443-757-5802 }\end{array}$} \\
\hline
\end{tabular}

\section{ABSTRACT}

A novel docking seal was developed for the main interface seal of NASA's Low Impact Docking System (LIDS). This interface seal was designed to maintain acceptable leak rates while being exposed to the harsh environmental conditions of outer space. In this experimental evaluation, a candidate docking seal assembly called Engineering Development Unit (EDU58) was characterized and evaluated against the Constellation Project leak rate requirement. The EDU58 candidate seal assembly was manufactured from silicone elastomer S0383-70 vacuum molded in a metal retainer ring. Four seal designs were considered with unique characteristic heights. The leak rate performance was characterized through a mass point leak rate method by monitoring gas properties within an internal control volume. The leakage performance of the seals were described herein at representative docking temperatures of $-50,+23$, and $+50{ }^{\circ} \mathrm{C}$ for all four seal designs. Leak performance was also characterized at 100, 74, and 48 percent of full closure. For all conditions considered, the candidate seal assemblies met the Constellation Project leak rate requirement.

15. SUBJECT TERMS

Docking seal; Leakage; Elastomers; Permeation; Space seal; Permeability; Silicones

\begin{tabular}{|c|c|c|c|c|c|}
\hline \multicolumn{3}{|c|}{ 16. SECURITY CLASSIFICATION OF: } & \multirow{2}{*}{$\begin{array}{l}\text { 17. LIMITATION OF } \\
\text { ABSTRACT } \\
\text { UU }\end{array}$} & \multirow{2}{*}{$\begin{array}{l}\text { 18. NUMBER } \\
\text { OF } \\
\text { PAGES } \\
15\end{array}$} & \multirow{2}{*}{$\begin{array}{l}\text { 19a. NAME OF RESPONSIBLE PERSON } \\
\text { STI Help Desk (email:help@sti.nasa.gov) } \\
\text { 19b. TELEPHONE NUMBER (include area code) } \\
\text { 443-757-5802 }\end{array}$} \\
\hline $\begin{array}{l}\text { a. REPORT } \\
\text { U }\end{array}$ & $\begin{array}{l}\text { b. ABSTRACT } \\
\text { U }\end{array}$ & $\begin{array}{l}\text { c. THIS } \\
\text { PAGE } \\
\text { U }\end{array}$ & & & \\
\hline
\end{tabular}



